\title{
OPEN Development of high slip-resistant footwear outsole using rubber surface filled with activated carbon/ sodium chloride
}

\author{
Toshiaki Nishi $\circledast^{1,2 \bowtie}$, TakeshiYamaguchi ${ }^{2,3}$ \& Kazuo Hokkirigawa ${ }^{2}$
}

High slip-resistant footwear outsoles can reduce the risk of slip and fall on wet and icy surfaces. Falls on wet and icy surfaces can cause serious life-threatening injuries, especially for older adults. Here we show that footwear outsoles using the rubbers filled with activated carbon or sodium chloride produce higher friction force and reduce the slip rate in walking. We have identified that small depressions were formed on outsole materials filled with activated carbon or sodium chloride during friction between the rubber and surface leading to some air ingress into the interface. While there are air bubbles between the rubber and surface, real contacts are surrounded by water with negative pressure (Laplace pressure). It is considered that the negative pressure promotes real contact formation, which causes high friction. We consider that the outsole materials filled with activated carbon or sodium chloride can reduce the risk of slip-and-fall accidents.

Slip-and-fall accidents can be a risk factor for serious injuries in daily life ${ }^{1}$. This risk can be reduced by improving slip-resistant outsoles on slippery floors such as wet smooth floors ${ }^{2}$. Thus, there has been many attempts to improve the slip resistance of outer soles by structure designing ${ }^{3-5}$ and material designing ${ }^{6}$. On wet floors, water intervention causes low real contact area, which results in low friction ${ }^{7}$. In the friction of soft matter such as outsole rubber and water between two substrates can be eliminated based on the surface free energy called the dewetting effect ${ }^{8,9}$. In addition, it would be meaningful to make a wetting state non-uniform because non-uniform wetting promotes real contact formation, which enlarges friction coefficient $\mu^{10,11}$. Here, non-uniform wetting is defined by a heterogeneous interface between the rubber (hydrophobic) and hydrogel patch (hydrophilic) on floor ${ }^{10}$ and the heterogeneous interface between rubber and floor, which contains air bubbles (hydrophobic) in water (hydrophilic) ${ }^{11}$. When the diameter of pores on hydrophobic material is less than $10-100 \mu \mathrm{m}$, water cannot penetrate into the pores ${ }^{12}$; thus, non-uniform wetting can be achieved with the existing air pockets (small pores) on the rubber surface. Here, the influence of roughness of rubber surface on friction behaviour has been reported $^{13,14}$, but, to enclose air in the pores, the size of pores is needed to control in smaller scale $(10-100 \mu \mathrm{m})$ in comparison with this previous study. Considering the wear of rubber surface containing air pockets in a practical use of outsole, it is better to add small gaps that can turn into air pockets by the atmosphere. Here, activated carbon (AC) and sodium chloride (SC) particles can be suitable candidates as filler materials that create air pockets on the rubber surfaces. AC is one of the carbon-based porous materials and some pores are expected to form on the rubber outsole surface with the addition of AC; moreover, since the water-soluble SC on the rubber surface can be removed by exposing it to water, air pockets form on the rubber surface. Additionally, AC and SC are chemically and thermally stable and do not affect chemical reactions in the cross-linking process; therefore, rubber with AC or SC can be useful for outsole materials.

Different types of filler materials such as carbon black and silica have been added to rubber to improve the stiffness, tensile strength, tear strength, and wear resistance ${ }^{15-17}$. Even the specific surface area of carbon black is not smaller than that of AC, AC is chemically similar to carbon black ${ }^{18}$. Here, AC can be produced from biomass materials, such as wood, crop residues, sawdust, coconut shell, animal waste, aquatic plants, algae, tannery solid waste, dead leaf, and bamboo ${ }^{19-24}$. Thus, to replace carbon black to AC in a view point of environment protection, the physical properties of rubber with $\mathrm{AC}$ has been eagerly investigated ${ }^{24,25}$, but the friction behaviour of rubber

\footnotetext{
${ }^{1}$ Institute of Sport Science, ASICS Corporation, 6-2-1, Takatsukadai, Nishi-ku, Kobe, Hyogo 651-2271, Japan. ${ }^{2}$ Department of Finemechanics, Graduate School of Engineering, Tohoku University, 6-6-01 Aramaki Aza-Aoba, Aoba-ku, Sendai 980-8579, Japan. ${ }^{3}$ Graduate School of Biomedical Engineering, Tohoku University, 6-6-01 Aramaki Aza-Aoba, Aoba-ku, Sendai 980-8579, Japan. ${ }^{\varpi}$ email: toshiaki.nishi@asics.com
} 
with AC has not been reported, On the other hand, SC has not reinforcing effect and the friction behaviour of rubber with SC has not also been reported; thus, this study aims to develop the slip resistance of outsole rubber materials filled with AC or SC and to clarify real contact formation and friction behaviour between these rubbers and floors. Therefore, vulcanised isoprene rubber (IR) with/without AC or SC were prepared at different contents controlling the elastic modulus $E$, and hemispheres and outsoles were prepared using these materials. The friction test using rubber hemispheres and outsoles, and slip-resistance test using outsoles in stepping motion was conducted.

\section{Results and discussion}

Friction behaviours of hemisphere specimens. Effects of AC or SC addition on friction coefficient under wet conditions. The outsole rubber materials filled with AC or SC (Fig. 1a) were prepared, as listed in Table 1, and the contact condition and friction force of these samples were measured during friction on water-covered glass (Fig. 1b). Here, localization of air pockets (pinholes) for rubber with AC or SC were not observed in Fig. 1a. Considering the median size of AC was about $50 \mu \mathrm{m}$, most of AC surface was covered with rubber matrix, but partially protrudes to the surface. And, there were air pockets corresponding to the size of SC particles (the median size of SC was $11.1 \mu \mathrm{m}$ ). Figure 1c-e show the distribution of real contacts (red area), air-covered area (white area) and water-covered area (blue area) for R1, AC3 and SC3 at $d=5.00 \mathrm{~mm}$, respectively. Here, the results at these conditions in Fig. 1c-e are shown as representative results. For all rubbers including the other rubber in Fig. 1c-e, many real contacts were formed within an elliptic shape whose minor axis was parallel to the sliding direction. These results resulted in the macroscopic strain in each hemisphere specimen as reported by Sahli et al. ${ }^{26,27}$. The air bubbles were formed only at rubber filled with AC and SC. It is considered that the air contained in each air bubble leaked from the air pockets on the rubber surface (Fig. 1a). Even after the friction test using hemisphere specimens was continuously conducted 5 times within five minutes, air bubbles were always observed for rubber filled with AC and SC. This result explains that the air in the air pockets was not completely replaced with water and continuously supplied air to the interface between the two substrates. Focusing on the outer edge of real contacts, it is confirmed that the outer edge did not contact with air bubbles, in other words, each real contact was surrounded by water. Similar trend has been also reported in the previous study ${ }^{11}$. Figure 1f-h reveal the changes in real contact area $A_{\mathrm{r}}$, air area (air-covered area) $A_{\mathrm{a}}$ and friction coefficient $\mu$ during the friction test using hemisphere specimens for R1, AC3 and SC3. It can be observed that the $A_{\mathrm{r}}$ value of R1 has clearly increased in the range of sliding distance $d=1.00-10.00 \mathrm{~mm}$; however, the variation of $\mu$ for R1 was relatively unstable at $d=0.00-5.00 \mathrm{~mm}$, while it showed a steady trend at $d=5.00-10.00 \mathrm{~mm}$. As seen from Fig. $1 \mathrm{~g}$, the $A_{\mathrm{a}}$ values are $0.00 \mathrm{~mm}^{2}$ at $d=0.00-10.00 \mathrm{~mm}$. The $A_{\mathrm{r}}$ values of AC3 and SC3 rubber materials decreased at $d=0.00-1.00 \mathrm{~mm}$ and then slightly increased at $d=1.00-10.00 \mathrm{~mm}$, while $\mu$ remained constant values during the friction test at $d=2.00-10.00 \mathrm{~mm}$. Interestingly, the $A_{\mathrm{a}}$ values of AC3 and SC3 are not zero during the friction test, which indicates that the air bubbles were trapped within the apparent contact area during a sliding process as shown in Fig. 1d,e. Because, the value of $\gamma_{\text {AirWater }}$ (corresponding to $\gamma_{\text {Water }}=72.8 \mathrm{~mJ} / \mathrm{m}^{2}$ ) is larger than $\gamma_{\text {AirRubber }}$ (corresponding to $\gamma_{\text {Rubber }}=24.2-26.0 \mathrm{~mJ} / \mathrm{m}^{2}$ ) and $\gamma_{\text {AirGlass }}\left(\right.$ corresponding to $\gamma_{\text {Glass }}=51.5 \mathrm{~mJ} / \mathrm{m}^{2}$ ), the total free energy can be minimised when the air bubbles contact with the surfaces of rubber and glass, which would enable the attachment of air bubbles within the apparent contact area. Figure $2 \mathrm{a}-\mathrm{c}$ indicate mean values and standard distribution of $A_{\mathrm{r}}, A_{\mathrm{a}}$ and $\mu$ respectively, for R1-5 (rubbers without AC or SC), AC3-7 (rubbers with AC) and SC3-7 (rubbers with SC) plotted against the elastic modulus $E$. It was observed that $A_{\mathrm{r}}$ values of all rubbers have decreased with the increase in $E$. While $A_{\mathrm{r}}$ at $6.4<E<6.8 \mathrm{MPa}$ increased for +39 and $+188 \%$ by adding AC and SC, respectively, the increasing rates of $A_{\mathrm{r}}$ at $12.9<E<14.3 \mathrm{MPa}$ were +30 and $+64 \%$ by adding $\mathrm{AC}$ and SC, respectively. In addition, the $A_{\mathrm{a}}$ values of R1 fluctuated around 0 in the range of $0-20 \mathrm{MPa}$ since it does not contain any air bubbles. However, the $A_{\mathrm{a}}$ values of $\mathrm{AC}$ and SC are $>0$ due to having air bubbles and decreased with the increase in $E$. The negative correlations between $A_{\mathrm{r}}$ and $E$ can be explained on the basis of Hertz contact theory wherein low $E$ enlarges apparent contact area $A_{0}{ }^{28}$. The negative correlations between $A_{\mathrm{a}}$ and $E$ for rubbers filled with AC and SC can also be explained on the basis of Hertz contact theory, because the increase in $A_{0}$ would enlarge potential area where air bubbles were formed. Regarding the dependency of $A_{\mathrm{r}}$ on $E$, Fig. $2 \mathrm{c}$ illustrates that there are negative correlations between $\mu$ and $E$, and that $\mu$ has increased by adding AC and SC, especially at $E<10 \mathrm{MPa}$. Figure 2d-f reveal the values of $A_{\mathrm{r}}, A_{\mathrm{a}}$ and $\mu$ for R3 (rubbers without AC or SC), AC1, AC2, AC5, AC8 (rubbers filled with AC), SC1, SC2, SC5, SC8 and SC9 (rubbers filled with SC) plotted against AC or SC content. Figure 2e illustrates that air bubbles were formed by adding AC and SC, while the $A_{\mathrm{a}}$ values showed up-down trends with AC and SC contents; however, as observed in Fig. $2 \mathrm{~d}, \mathrm{f}, A_{\mathrm{r}}$ and $\mu$ values have increased with the increase in AC and SC contents. Figure $2 \mathrm{~g}$ reveals the proportional relationship between $\mu$ and $A_{\mathrm{r}}$ for all conditions. This result demonstrates that the real contact formation was promoted by adding AC and SC, which leads to increase in $\mu$ due to improvements in adhesion ${ }^{29,30}$; thus, the real contact formation was promoted by adding AC and SC, which increased $\mu$.

The high friction mechanism of rubber with AC or SC. According to Eqs. (1) and (2), real contacts of soft material on a floor as shown in Fig. 3a thermodynamically expand when the spreading coefficient $S$ has a negative value in water or the work of adhesion $W$ has a positive value in air, and this phenomenon is called a dewetting effect ${ }^{8,9,31}$. $S$ and $W$ correspond to the parameter of quantifying wettability between rubber and floor under unlubricated and lubricated conditions, respectively, and these parameters can be calculated from the following equations $^{12,32}$ :

$$
W=\left(\gamma_{\mathrm{R}}+\gamma_{\mathrm{G}}\right)-\gamma_{\mathrm{RG}}
$$


a Rubber without activated Rubber with

carbon/sodium chloride activated carbon (AC5) sodium chloride (SC5)

(R3)
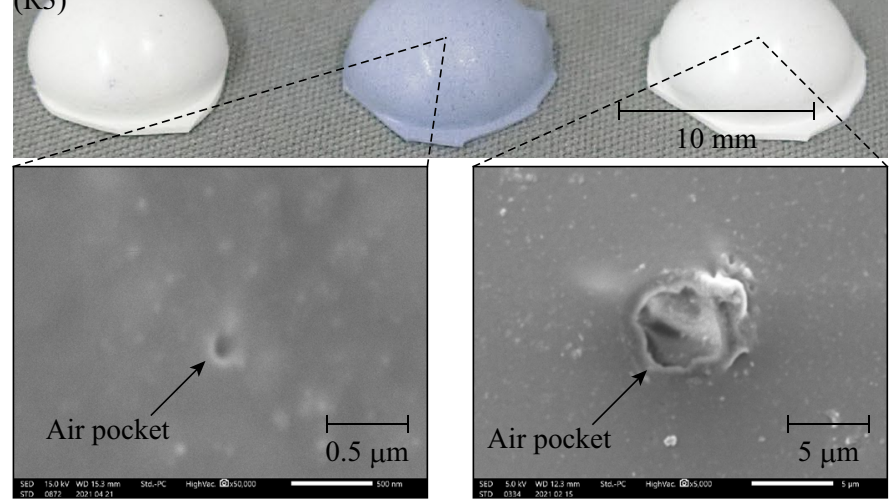

b

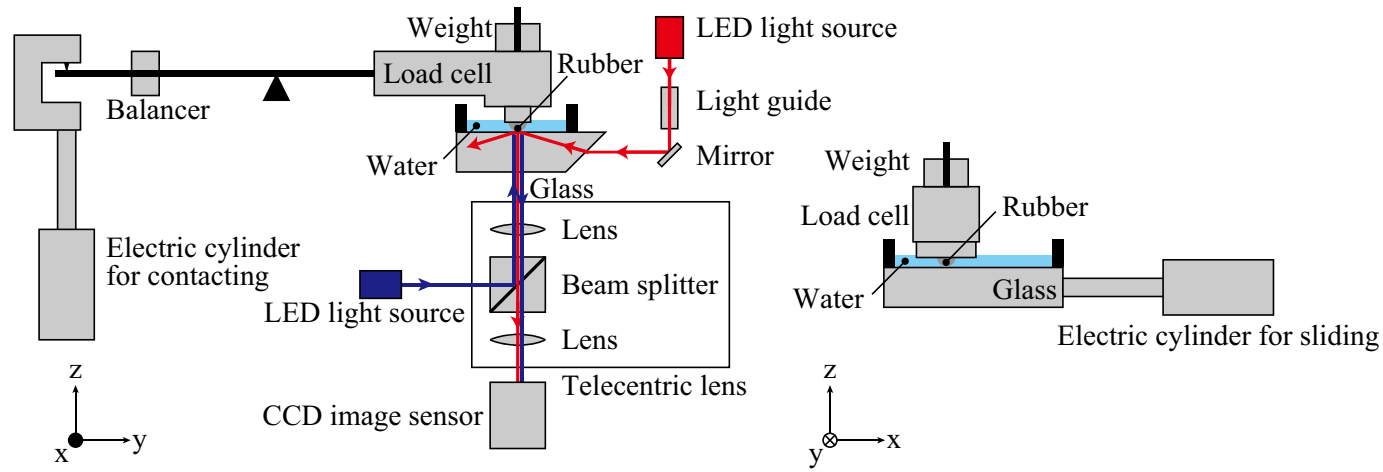

$\underset{\text { Sliding direction of glass }}{\longrightarrow}$
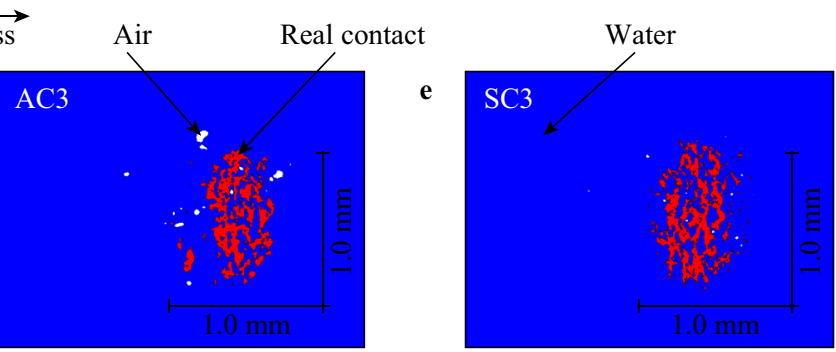

O Without activated carbon / sodium chloride

With activated carbon

○ With sodium chloride
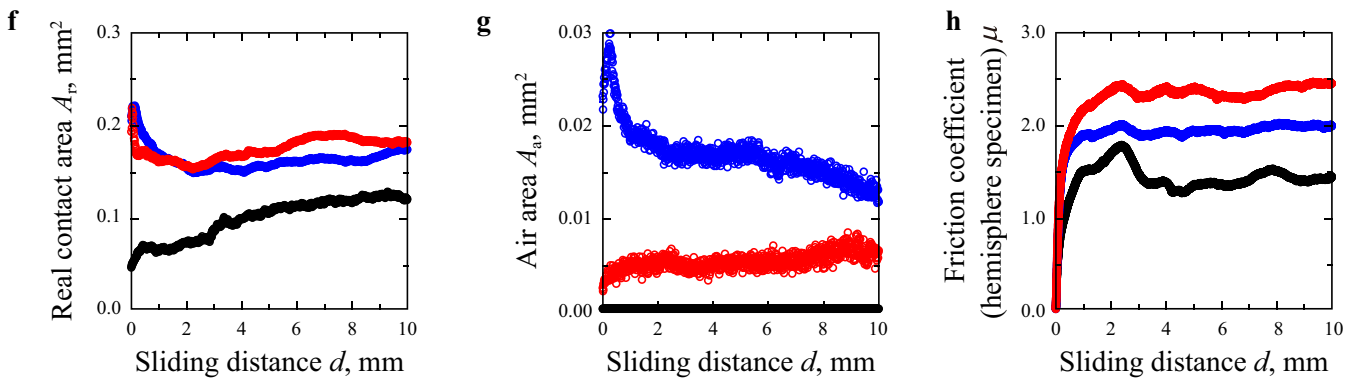

Figure 1. Overview of hemisphere specimens and obtained results in friction test using hemisphere specimens. (a) Images of hemisphere specimens (R3, AC5, and SC5). (b) Schematic of the experimental system for friction test. (c-e) Distribution of real contact, air bubble and water at $d=5.00 \mathrm{~mm}$ for R1, AC3 and SC3. (f-h), Changes in the real contact area $\left(A_{\mathrm{r}}\right)$, air area $\left(A_{\mathrm{a}}\right)$ and friction coefficient $(\mu)$ for R1, AC3 and SC3. 


\begin{tabular}{|c|c|c|c|c|c|c|c|}
\hline & AC content (vol\%) & SC content (vol\%) & Elastic modulus (MPa) & Tensile strength (MPa) & Tear strength $(\mathrm{N} / \mathrm{mm})$ & $\begin{array}{l}\text { Surface free energy } \gamma \\
\left(\mathrm{m} J / \mathrm{m}^{2}\right)\end{array}$ & $\begin{array}{l}\text { Spreading coefficient } \\
\text { contacting with glass } \\
\text { in water } S\left(\mathrm{~mJ} / \mathrm{m}^{2}\right)\end{array}$ \\
\hline R1 & 0.0 & 0.0 & 5.6 & 14.0 & 75.9 & 24.2 & -29.9 \\
\hline $\mathrm{R} 2$ & 0.0 & 0.0 & 8.7 & 14.4 & 77.3 & 24.7 & -29.9 \\
\hline R3 & 0.0 & 0.0 & 9.9 & 17.9 & 78.0 & 25.9 & -31.4 \\
\hline $\mathrm{R} 4$ & 0.0 & 0.0 & 12.5 & 19.9 & 85.5 & 24.9 & -30.0 \\
\hline R5 & 0.0 & 0.0 & 15.4 & 16.7 & 72.3 & 26.0 & -31.5 \\
\hline $\mathrm{AC} 1$ & 0.83 & 0.0 & 6.6 & 20.0 & 70.9 & 24.2 & -29.9 \\
\hline $\mathrm{AC} 2$ & 1.5 & 0.0 & 6.6 & 16.3 & 69.0 & 24.8 & -29.9 \\
\hline AC3 & 2.4 & 0.0 & 4.2 & 14.2 & 36.4 & 25.7 & -31.4 \\
\hline AC4 & 2.5 & 0.0 & 5.4 & 14.7 & 43.1 & 24.2 & -29.9 \\
\hline AC5 & 2.3 & 0.0 & 6.8 & 14.6 & 57.9 & 26.0 & -31.5 \\
\hline AC6 & 2.2 & 0.0 & 8.6 & 14.5 & 68.8 & 25.7 & -31.4 \\
\hline AC7 & 2.3 & 0.0 & 14.3 & 15.6 & 74.8 & 25.8 & -31.4 \\
\hline AC8 & 2.9 & 0.0 & 6.9 & 12.4 & 39.7 & 25.8 & -31.4 \\
\hline $\mathrm{SC} 1$ & 0.0 & 1.0 & 10.9 & 17.0 & 75.7 & 25.3 & -30.0 \\
\hline SC2 & 0.0 & 2.0 & 10.2 & 18.1 & 74.5 & 24.6 & -29.9 \\
\hline SC3 & 0.0 & 3.0 & 6.4 & 18.3 & 77.2 & 24.6 & -29.9 \\
\hline SC4 & 0.0 & 3.0 & 8.9 & 16.5 & 71.3 & 24.5 & -29.9 \\
\hline SC5 & 0.0 & 3.0 & 10.8 & 16.8 & 77.0 & 24.9 & -31.3 \\
\hline SC6 & 0.0 & 3.0 & 13.2 & 16.5 & 70.9 & 24.8 & -29.9 \\
\hline SC7 & 0.0 & 3.0 & 17.4 & 14.4 & 75.5 & 25.1 & -31.4 \\
\hline SC8 & 0.0 & 4.0 & 10.8 & 16.0 & 71.7 & 24.5 & -29.9 \\
\hline SC9 & 0.0 & 4.0 & 11.3 & 14.0 & 67.9 & 24.2 & -29.9 \\
\hline
\end{tabular}

Table 1. Content of AC or SC and physical properties among prepared rubbers.

$$
S=\gamma_{\mathrm{RG}}-\left(\gamma_{\mathrm{RW}}+\gamma_{\mathrm{GW}}\right)
$$

where the subscripts $\mathrm{R}, \mathrm{G}$ and $\mathrm{W}$ correspond to rubber, glass and water, respectively; $\gamma_{\mathrm{i}}$ is the surface free energy of material I and $\gamma_{i j}$ is the interfacial free energy between materials $i$ and $j$. In Kaelble and Uy theory, $\gamma_{i}$ is defined as the sum of dispersion term $\gamma_{i}^{\mathrm{d}}$ and polar term $\gamma_{i}^{\mathrm{p}}\left(\gamma_{i}=\gamma_{i}^{\mathrm{d}}+\gamma_{i}^{\mathrm{p}}\right)$, and $\gamma_{i j}$ is obtained via the following equations $s^{12,33}$ :

$$
\gamma_{i j}=\left(\sqrt{\gamma_{i}^{d}}-\sqrt{\gamma_{j}^{d}}\right)^{2}+\left(\sqrt{\gamma_{i}^{p}}-\sqrt{\gamma_{j}^{p}}\right)^{2}
$$

The dewetting effect is explained on the basis of free energy of the system $G$, which is a convex quadratic function of the real contact size $R$ in the following equations $s^{8,9}$ :

$$
G \propto-|S| R^{2}+E e^{2} R
$$

where $e$ indicates the clearance between two substrates. This equation explains that when $R$ is higher than $R_{\mathrm{c}}=E e^{2} /$ $|S|$, the real contact thermodynamically expands due to the negative values of $G$ and negatively increasing rate of $G$. It has been theoretically and experimentally reported that real contact formation can be promoted as $R_{c}$ decreases ${ }^{11}$. In addition, this theory has been developed to explain for a non-uniform wetting state where there are some air bubbles between two substrates in water, and the real contacts are surrounded by water meniscus as shown in Fig. $3 \mathrm{~b}^{11}$. It has been reported that $G$ and $R_{\mathrm{c}}$ for such a condition are obtained in the following equations ${ }^{11}$ :

$$
\begin{gathered}
G \propto-(2 W+S) R^{2}+E e^{2} R \\
R_{\mathrm{c}}=\frac{E e^{2}}{2 W+S} .
\end{gathered}
$$

The pressure in water meniscus is negative at $\cos \theta_{\mathrm{R}}+\cos \theta_{\mathrm{G}}>0, E e^{2} / I S I>E e^{2} /(2 W+S)$; thus, if $\cos \theta_{\mathrm{R}}+\cos \theta_{\mathrm{G}}>0$, $R_{\mathrm{c}}$ decreases due to the air bubbles between two substrates in water and dewetting effect can be promoted. Here, $\theta_{\mathrm{i}}$ is the contact angle of water on material i. Equations (5) and (6) also explain that the dewetting effect is sensitive to the value of $e$. However, as shown in Fig. 3c,e is not always constant, depending on the volume of water meniscus; thus, the clearance at the outer edge of the water meniscus $\left(e_{1}\right)$ can be larger than the inner edge of 
a

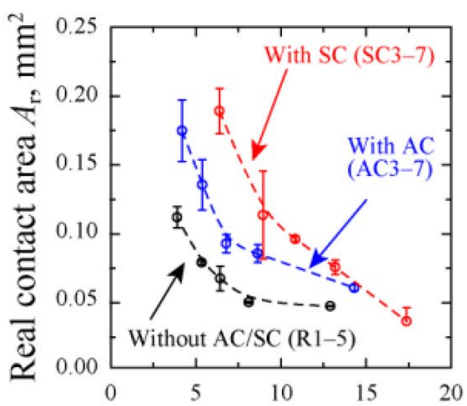

Elastic modulus $E, \mathrm{MPa}$

d
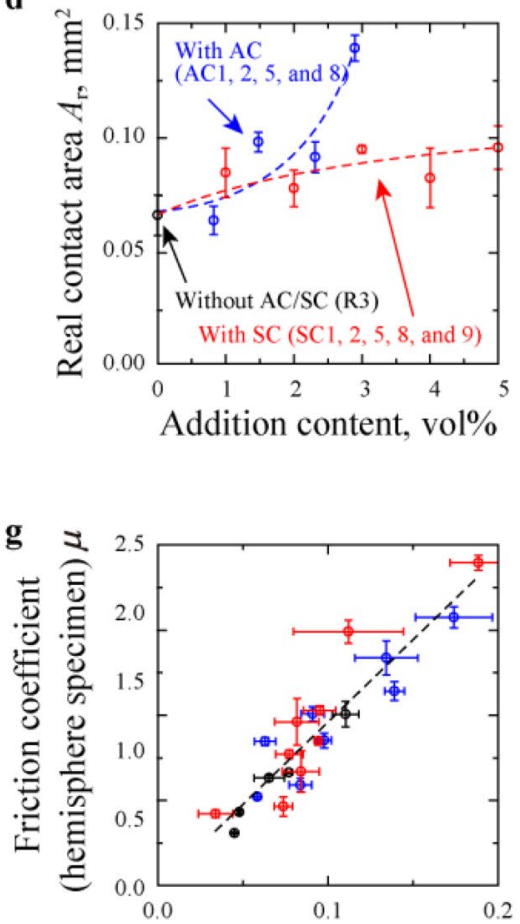

Real contact area $A_{\mathrm{r}}, \mathrm{mm}^{2}$ b

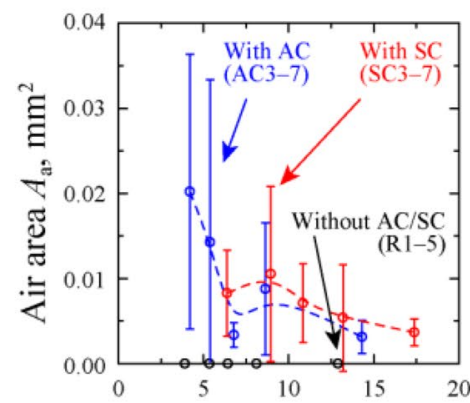

Elastic modulus $E, \mathrm{MPa}$

e

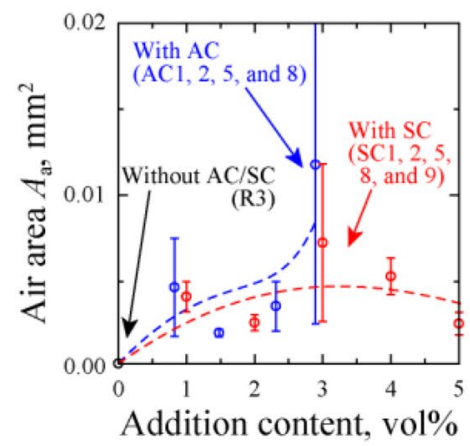

c

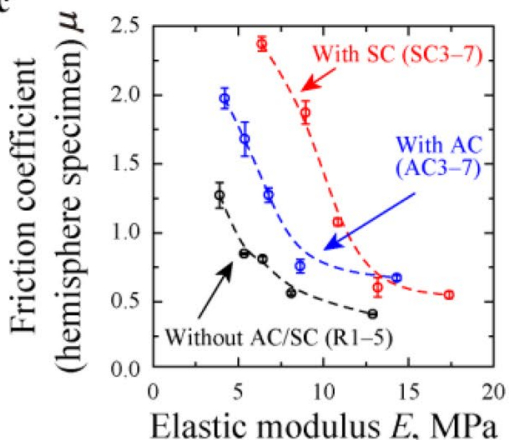

f

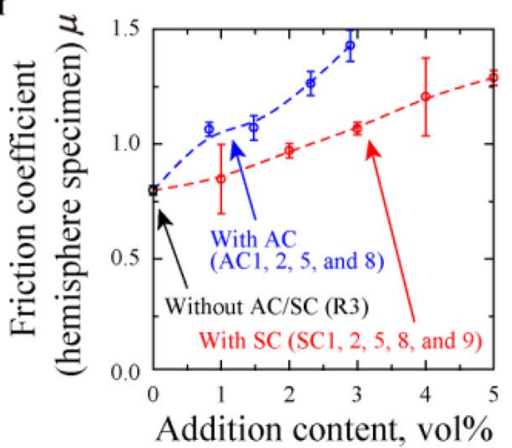

o Without activated carbon / sodium chloride

O With activated carbon

O With sodium chloride

Figure 2. Measured parameters in friction test using hemisphere specimens. (a-c) Influence of elastic modulus $(E)$ on the real contact area $\left(A_{\mathrm{r}}\right)$, air area $\left(A_{\mathrm{a}}\right)$ and friction coefficient $(\mu)$ for R1-5, AC3-7 and SC3-7. (d-f) $A_{\mathrm{r}}, A_{\mathrm{a}}$ and $\mu$ versus the content of $\mathrm{AC}$ and SC for R3, AC1, AC2, AC5, AC8, SC1, SC2, SC5, SC8 and SC9. (g) Relationship between $\mu$ and $A_{\mathrm{r}}$.

the water meniscus $\left(e_{0}\right)$. Considering that the pressure in water meniscus is determined by $e_{1}$, the values for $G$ and $R_{\mathrm{c}}$ for $e_{0} \neq e_{1}$ can be determined by the following equations:

$$
\begin{gathered}
G \propto-\left\{2 \frac{e_{0}}{e_{1}} W+\left(2 \frac{e_{0}}{e_{1}}-1\right) S\right\} R^{2}+e_{0}^{2} E R \\
R_{c}=\frac{e_{0}^{2} E}{2 \frac{e_{0}}{e_{1}} W+\left(2 \frac{e_{0}}{e_{1}}-1\right) S} .
\end{gathered}
$$

As confirmed in Fig. 1d,e, the real contacts were surrounded by water meniscus for rubber filled with AC and SC; thus, $R_{\mathrm{c}}$ for rubber filled with AC and SC can be estimated on the basis of Eq. (8), while $R_{\mathrm{c}}$ for rubber without AC and SC is defined as $R_{\mathrm{c}}=E e_{0}^{2} / \mathrm{ISI}$. Here, as the volume of water meniscus increases, the outer edge of the water meniscus reaches to the outer edge of apparent contact and $e_{1}$ increases to the depth of lubricant on the glass (more than $1 \mathrm{~mm}$ ), while the value of $e_{0}$ would not drastically change. Thus, the increase of volume of water meniscus induces $e_{0} / e_{1} \approx 0$, and Eq. (8) approaches to $R_{\mathrm{c}}=E e_{0}^{2} / I S I$. On the other hand, if $e_{0} / e_{1}>1$ when the volume of water meniscus is enough small, Eq. (8) explains that $R_{\mathrm{c}}$ decreases and the dewetting effect increases, but such a situation is also up to the surface geometry. Figure $3 \mathrm{~d}$ illustrates the histogram of $e$ around real contacts 
a
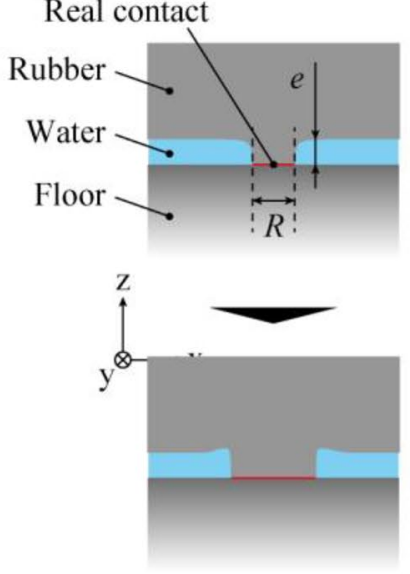

d

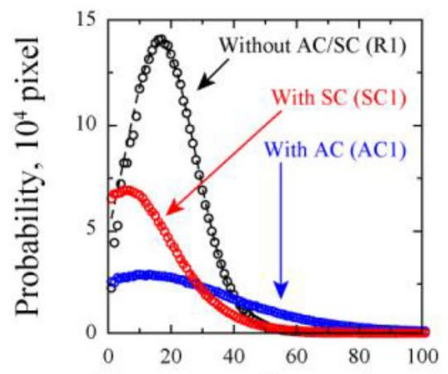

Clearance at inner edge of

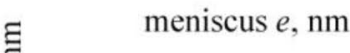

g

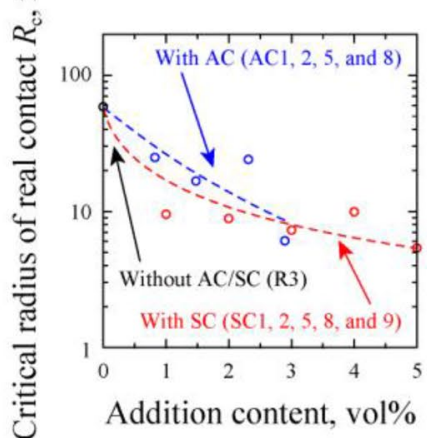

j

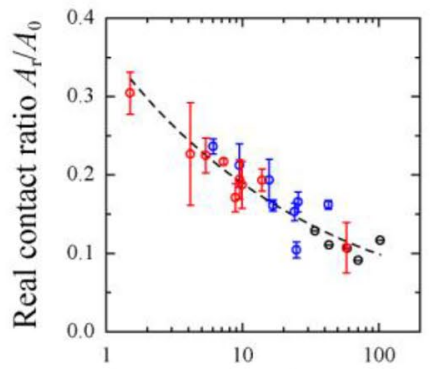

b
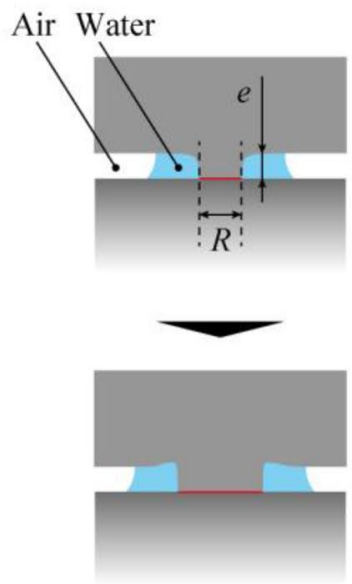

e

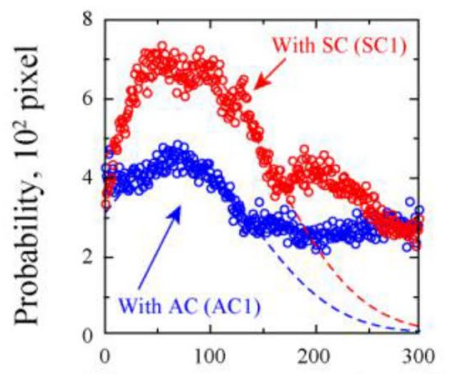

Clearance at outer edge of meniscus $e, \mathrm{~nm}$

h

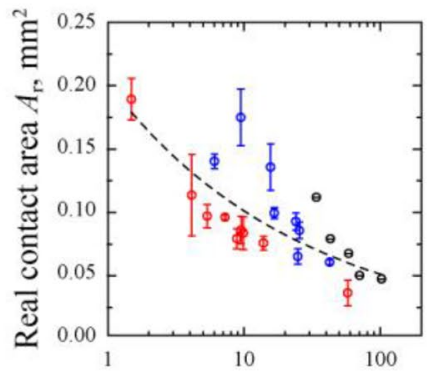

Critical radius of real contact $R_{\mathrm{c}}, \mathrm{nm}$

f

i
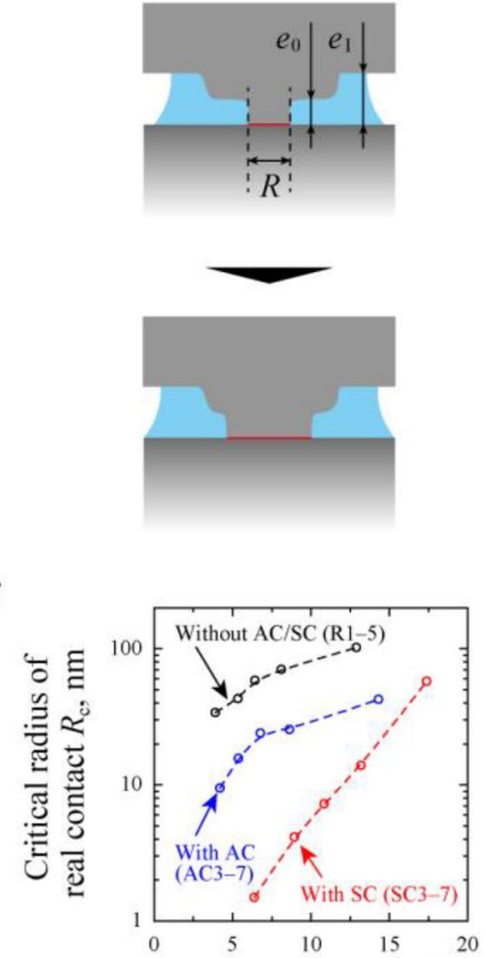

Elastic modulus $E, \mathrm{MPa}$

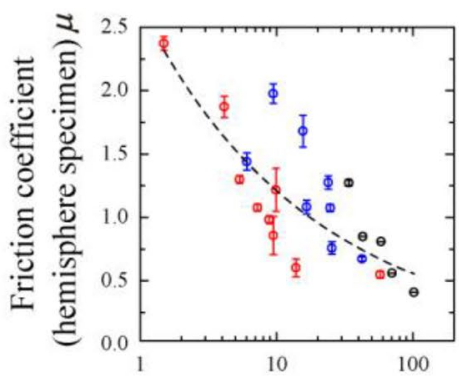

Critical radius of real contact $R_{\mathrm{c}}, \mathrm{nm}$

k

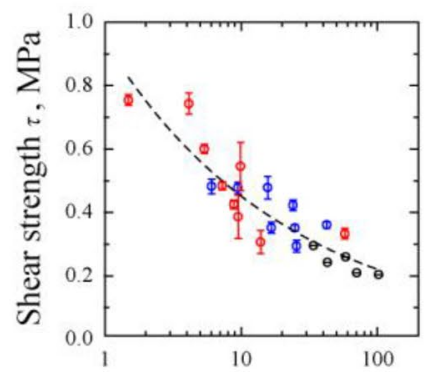

O Without activated carbon / sodium chloride

o With activated carbon

o With sodium chloride

Critical radius of real contact $R_{\mathrm{c}}, \mathrm{nm} \quad$ Critical radius of real contact $R_{\mathrm{c}}, \mathrm{nm}$

Figure 3. Obtained parameters relating to dewetting effect. $(\mathbf{a}-\mathbf{c})$ Schematic of real contact formation based on the dewetting effect: (a) uniform wetting; (b) non-uniform wetting but uniform clearance in the water meniscus; (c) non-uniform wetting and non-uniform clearance in the water meniscus. (d, e) Histograms of clearance at the inner (d) and outer (e) edges of the meniscus for R1, AC3 and SC3. (f, g) Critical radius of real contact $\left(R_{\mathrm{c}}\right)$ plotted against elastic modulus $(E)$ for R1-5, AC3-7 and SC3-7 and addition content for R3, AC1, AC2, AC5, AC8, SC1, SC2, SC5, AC8, and SC9. (h, i) Real contact area $\left(A_{\mathrm{r}}\right)$ and friction coefficient $(\mu)$ versus $R_{\mathrm{c} \cdot}(\mathbf{j}, \mathbf{k})$ Real contact ratio $\left(A_{\mathrm{r}} / A_{0}\right)$ and shear strength $(\tau)$ versus $R_{\mathrm{c}}$. 
for hemisphere specimens of $\mathrm{R} 1, \mathrm{AC} 1$ and SC1, and Fig. 3e indicates the histogram of $e$ at the outer edge of water meniscus for hemisphere specimens of $\mathrm{AC} 1$ and SC1. The value of $e$ on each pixel around real contacts and at the outer edge of the water meniscus was extracted from the measured distribution of $e$ at $d=5.00-10.00 \mathrm{~mm}$ using MATLAB software (R2016b, The MathWorks, Inc.). Figure 3d,e show that each histogram has a single peak. In this study, the peak value for histogram at the inner and outer edge of water meniscus was defined as $e_{0}$ and $e_{1}$, respectively. Figure $3 \mathrm{f}, \mathrm{g}$ display the influence of $E$ and addition amount of AC or SC on $R_{\mathrm{c}}$, which was calculated from $S, W, e_{0}$ and $e_{1}$. It was confirmed that $R_{\mathrm{c}}$ increased with increase in $E$ and decreased with increase in AC and SC content. Especially at $E<10 \mathrm{MPa}, R_{\mathrm{c}}$ drastically decreased for rubbers filled with SC. In Fig. 3h,i, $A_{\mathrm{r}}$ and $\mu$ are plotted against $R_{\mathrm{c}}$. Overall, $A_{\mathrm{r}}$ and $\mu$ decreased with increase in $R_{\mathrm{c}}$. Considering the fact that $A_{\mathrm{r}}$ and $\mu$ can increase with the apparent contact area $A_{0}$ determined by $E$ in the Hertz contact theory ${ }^{28}$, the real contact ratio $A_{\mathrm{r}} / A_{0}$ and the shear strength $\tau$ (friction force divided by $A_{0}$ ) were calculated and plotted against $R_{\mathrm{c}}$ in Fig. 3j,k. Figure 3j,k indicate negative correlations in $A_{\mathrm{r}} / A_{0}-R_{\mathrm{c}}$ and $\tau-R_{\mathrm{c}}$ curves. Defining the approximate lines in Fig. $3 \mathrm{~h}-\mathrm{k}$ as exponential function, the correlation coefficients of $A_{\mathrm{r}} / A_{0}-R_{\mathrm{c}}$ and $\tau-R_{\mathrm{c}}$ curves were 0.82 and 0.81 , respectively, while that of $A_{\mathrm{r}}-R_{\mathrm{c}}$ and $\mu-R_{\mathrm{c}}$ curves were 0.59 and 0.61 , respectively. These results suggest that real contact formation in apparent contact based on the dewetting effect was promoted as $R_{\mathrm{c}}$ got decreased and that $\tau$ increased by promoting the real contact formation. Therefore, considering that the real contact formation was promoted by adding AC or SC to rubber, especially at $E<10 \mathrm{MPa}$, and that $A_{0}$ decreased with $E$, it is reasonable to add $\mathrm{AC}$ or SC to soft rubber to achieve high friction.

Friction behaviours of outer soles. The mounting of footwear outsole rubber materials with/without AC or SC is shown in Fig. $4 \mathrm{a}-\mathrm{c}$, and their slip resistance on water-covered smooth floor was measured (Fig. 4d). Figure $4 \mathrm{e}, \mathrm{f}$ reveal the variation of $\mu$ values measured using footwear with the dependence of $E$ and content of AC and SC. Compared to the results in the friction test using hemisphere specimens, the $\mu$ values decreased with increase in $E$, increased with the increase in AC or SC content. For the R1, AC3 and SC3 (rubbers made from the softest master batch: MB1), the $\mu$ increased by $+52.8 \%$ and $+46.1 \%$ with the addition of AC and SC, respectively, while for R5, AC7, and SC7 (rubbers made from the hardest master batch: MB5), the $\mu$ increased by $+2.7 \%$ and $+5.6 \%$ with the addition of AC and SC, respectively. This result explains the softer the higher friction effect of $\mathrm{AC}$ and SC addition. Figure $4 \mathrm{~g}$ indicates a positive correlation between $\mu$ for footwear outsole materials and hemisphere specimens, but this correlation was not proportional and the value range of $\mu$ for footwear was minute in comparison with those obtained from hemisphere specimens. These results demonstrate that AC and SC addition enlarged $\mu$ for footwear, especially at $E<10 \mathrm{MPa}$; however, the absolute values of $\mu$ for footwear were small because of differences in the contact pressure, the sliding velocity, and the macroscopic geometry in comparison with the friction test using hemisphere specimen.

Slip rate of shoes in stepping trial. The slip rate of each outsole materials in stepping motion (Fig. 5a) was measured. Figure 5b-d reveal slipping rate $\Phi$ of R1, R3, R5, AC3, AC5, AC7, SC3, SC5 and SC7 outsole materials as a variation for $E$ at the step length of $0.60,0.70$ and $0.80 \mathrm{~m}$, respectively. It was observed that the $\Phi$ for all outsole materials increased with increase in $E$, and this dependency got more significant with an increase in the step length, especially for rubber without AC and SC. In addition, it was observed that $\Phi$ decreased with the addition of AC and SC. Figure 5e-g indicate the relationship between $\Phi$ and $\mu$ for footwear. The $\Phi$ values drastically decreased at $\mu<0.19$ and remained in steady values at $\mu \geq 0.19$ regardless of step length, and the convergence value of $\Phi$ at $\mu \geq 0.19$ increased with step length. These results indicate that the higher $\mu$ values provide the lower risk of slipping at $\mu<0.19$, and that the risk of slipping at $\mu \geq 0.19$ was not zero and increased with step length due to the uncertainty in human motion such as the stepping speed, the angle of heel contact, lean angle of body, and so on. Focusing on the $\Phi-\mu$ curves at $\mu<0.19$, the decreasing rate of $\Phi$ decreased and got almost zero at $\mu=0.19$. Here, it is considered that the value of $\Phi$ was also depended on accidental changes in human motion, and that these accidental changes would be described by the Gauss distribution. Assuming that the relationship between $\Phi$ and $\mu$ for footwear is related to a Gaussian function, this relationship can be described by the mean value of friction coefficient $\mu_{0}$, the standard deviation of friction coefficient $\sigma$, and the convergence value of slipping rate $\Phi_{0}$, as shown in the following equation:

$$
\Phi=\left(1-\Phi_{0}\right) \frac{2}{\sqrt{\pi}} \int_{\frac{\mu-\mu_{0}}{\sigma}}^{\infty} e^{-t^{2}} \mathrm{~d} t+\Phi_{0}=\left(1-\Phi_{0}\right) \operatorname{erfc}\left(\frac{\mu-\mu_{0}}{\sigma}\right)+\Phi_{0} .
$$

The values of $\mu_{0}, \sigma$, and $\Phi_{0}$ for each stepping length condition were determined by fitting the measured and estimated values of $\Phi$ based on a least squares method. The calculated $\Phi-\mu$ curves are plotted as dash lines in Fig. 5e-g, and the calculated values of $\mu_{0}, \sigma$, and $\Phi_{0}$ are listed in Table 2 . Figure $5 \mathrm{e}-\mathrm{g}$ show that measured results were plotted on the fitting curves, and that all plots including error bar are plotted on these fitting curves. Here, $\Phi$ drastically decreased at $\mu_{0}+3 \sigma>\mu \geq \mu_{0}-3 \sigma$ and got saturated at $\mu \geq \mu_{0}+3 \sigma$. Since $\mu_{0}+3 \sigma=0.181-0.189$ as shown in Table 2, it is desirable to make $\mu>0.189$ to minimize the slipping risk in stepping motion. Figure $4 \mathrm{e}$ indicates that $\mu$ of footwear was $>0.189$ for rubbers filled with AC and SC at $E<10 \mathrm{MPa}$. For the outsole containing the same master batch MB3 (R3, AC5, and SC5), the measured values of $\mu$ using footwear were $0.169,0.196$ and 0.191 , respectively. Focusing on the case when the step length was $0.70 \mathrm{~m}$ (Fig. $5 \mathrm{f}$ ), $\Phi$ was $28.6 \%$ for R3, and decreased to $14.1 \%$ and $5.9 \%$ with addition of AC and SC, respectively. Moreover, $\Phi$ for AC5 and SC5 further decreased to $5.9 \%$ and $4.1 \%$, respectively, at $E<10 \mathrm{MPa}$. In summary, it is expected that the addition of AC or SC 


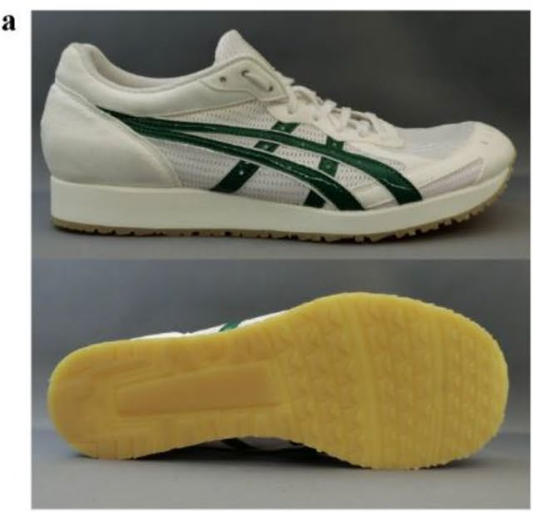

Rubber without activated carbon / sodium chloride (R3)

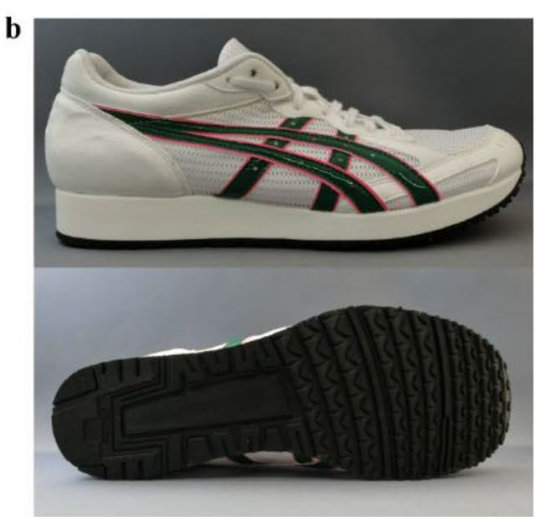

Rubber with activated carbon (AC5)

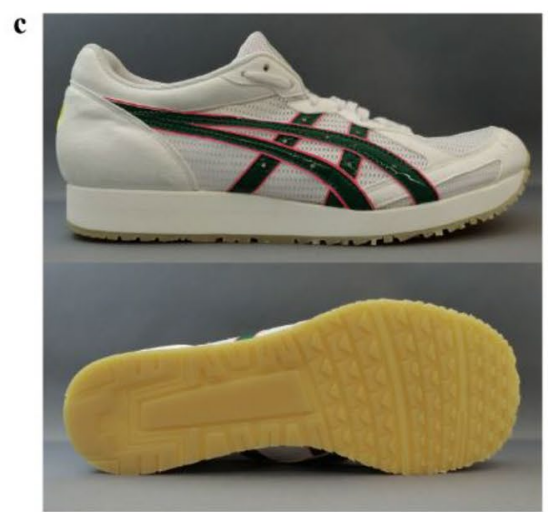

Rubber with sodium chloride (SC5)

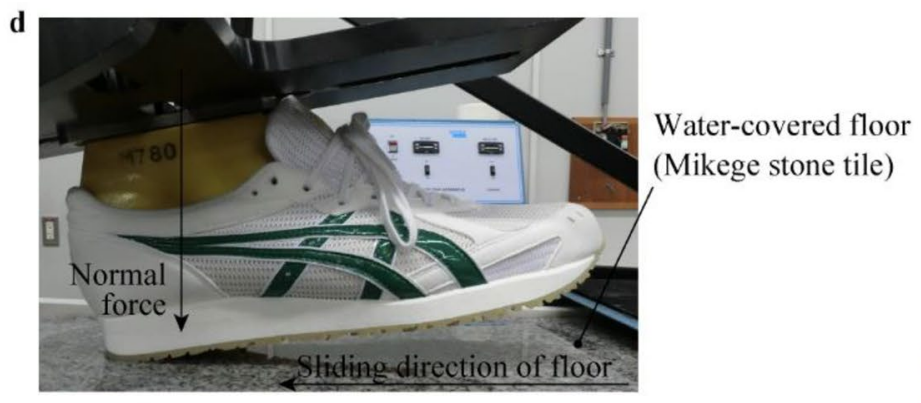

○ Without activated carbon / sodium chloride

○ With activated carbon

○ With sodium chloride

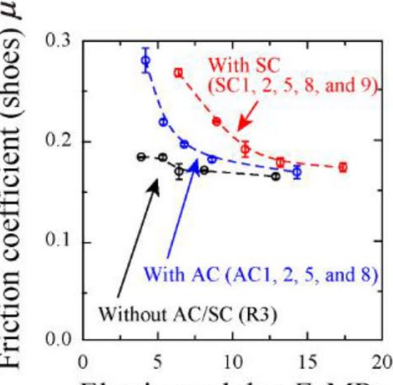

Elastic modulus $E, \mathrm{MPa}$ f

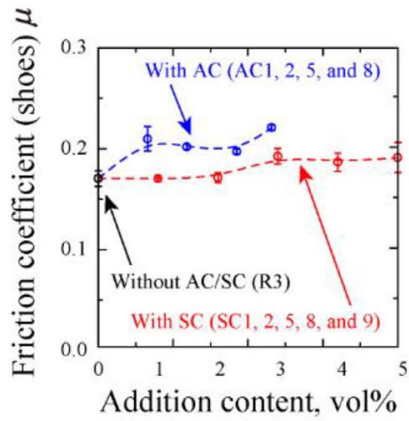

g

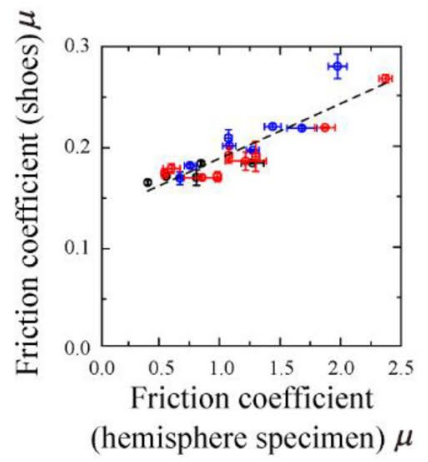

Figure 4. Overview and measured parameters in friction test using shoes. (a-c) Images of shoes with outer soles of R3, AC5 and SC5. (d) Schematic of the experimental system for friction test using shoes with a slip meter. (e, f) Influences of elastic modulus (E) and AC and SC content on the friction coefficient $(\mu)$ in friction tests using shoes. $\mathrm{g}$, Relationship between $\mu$ using shoes and hemisphere specimens for all rubbers.

to the soft rubber (especially for $E<10 \mathrm{MPa}$ ) will be useful to reduce slipping risk in a practical use of footwear, at least in a stepping motion.

\section{Methods}

Material preparation. Rubbers were prepared in three steps: The compounds were mixed at $100-130{ }^{\circ} \mathrm{C}$ for 5.5 min (first mixing process) using a kneader (DS3-10MWB, Nihon Spindle Manufacturing Co., Ltd., Amagasaki, Japan) and continued to be mixed at low temperatures of $30-50{ }^{\circ} \mathrm{C}$ (second mixing process) using open roll (KD-M2-8, Kneader Machinery Co., Ltd., Taiwan, China) and finally pressed at $160^{\circ} \mathrm{C}$ for 10 min (moulding process) using three types of moulds: sheet $(215 \mathrm{~mm} \times 130 \mathrm{~mm} \times 2.0 \mathrm{~mm})$, hemisphere (radius of curvature: $5.0 \mathrm{~mm}$ ) and outer-sole. As shown in Table 3, five rubber compositions (labelled as MB1-5) were prepared in the first mixing process using isoprene rubber (Nipol IR2200, Zeon Corporation, Tokyo, Japan), silica (Nipsil VN3, Tosoh Silica Corporaion, Tokyo, Japan), oil (P200, Sineikako Co., Ltd., Kobe, Japan), Bis(triethoxysilylpropyl) tetrasulfide (Si69, Evonik Industries Japan, Osaka, Japan), Stearic acid (50S, New Japan Chemical Co., Ltd., Osaka, Japan) and zinc oxide (activated zinc oxide No.2, Honjo Chemical Corporation, Osaka, Japan). The content of silica was controlled to change $E$. In the second process, surfer (\#200, Hosoi Chemical Co., Ltd., Oita, Japan), benzothiazolyl disulphide (Nocceler DM, Ouchi Shinko Chemical Industrial Co., Ltd., Tokyo, Japan), 
Water-covered floor (Mikege stone tile)

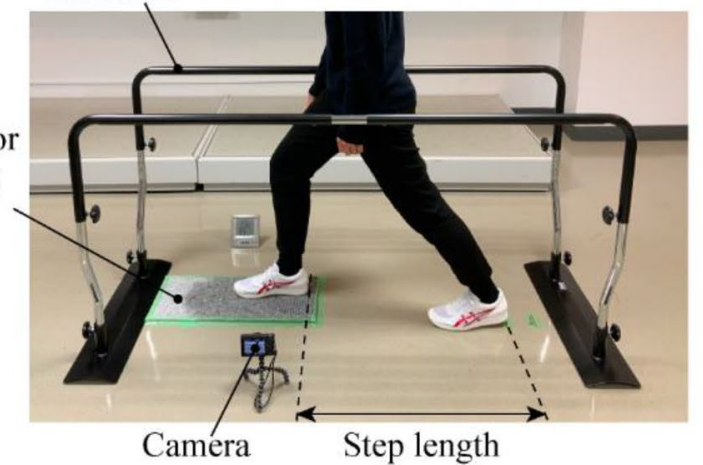

O Without activated carbon / sodium chloride

o With activated carbon

o With sodium chloride
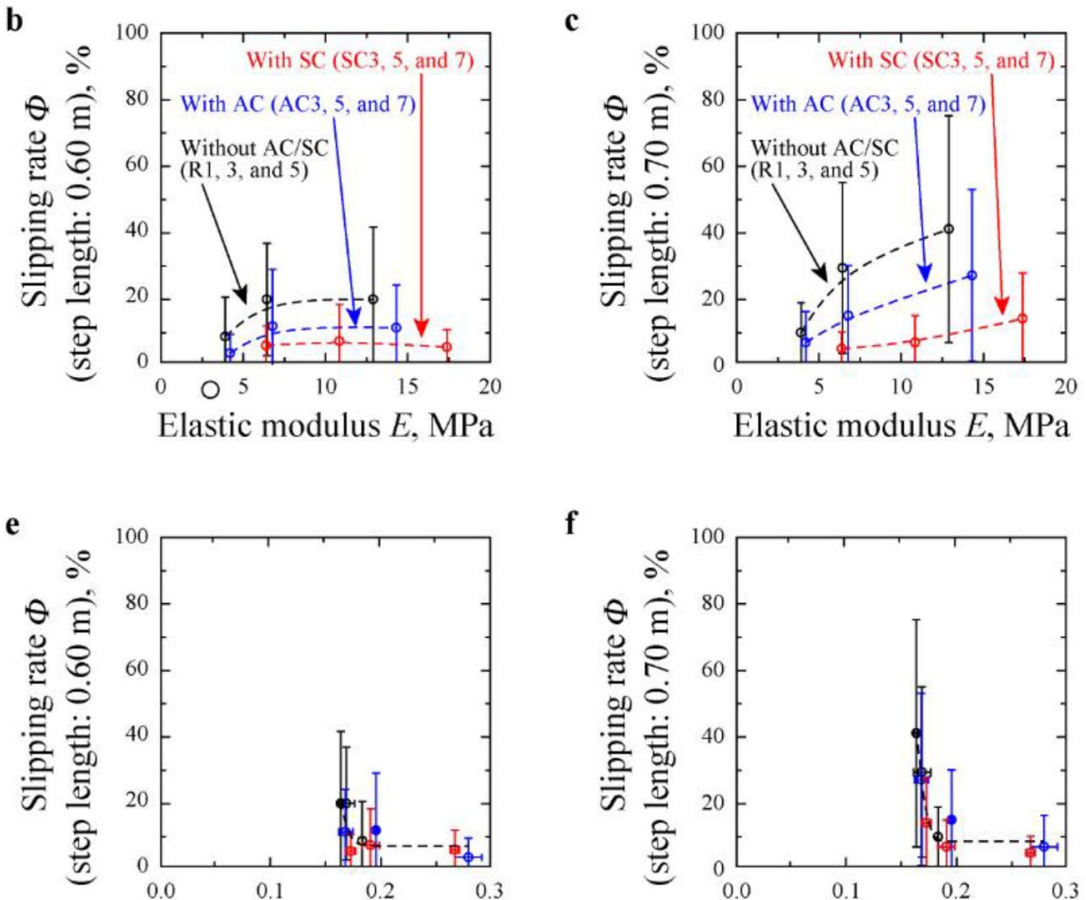

Friction coefficient (shoes) $\mu$ f

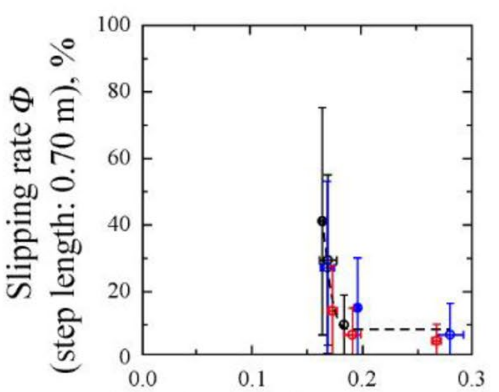

Friction coefficient (shoes) $\mu$ d

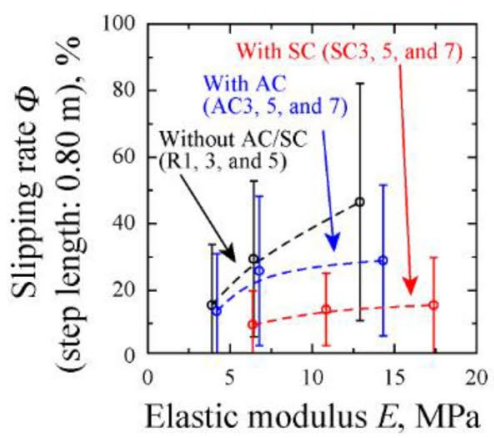

g

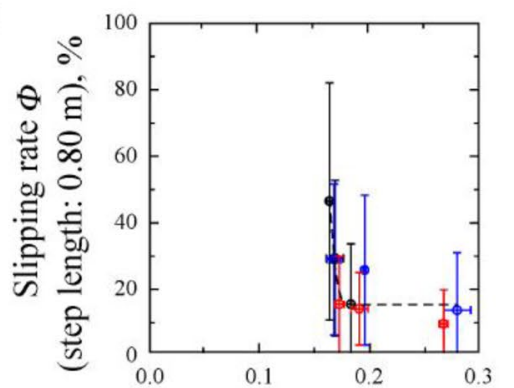

Friction coefficient (shoes) $\mu$

Figure 5. Overview and parameters obtained in slip-resistance test using shoes. (a) Experimental system under stepping motion. (b-d) Slipping rate $(\Phi)$ versus elastic modulus (E) for R1, R3, R5, AC3, AC5, AC7, SC3, SC5 and SC7. (e-g) $\Phi$ versus friction coefficient ( $\mu$ using shoes with outer soles of R1, R3, R5, AC3, AC5, AC7, SC3, SC5 and SC7.

\begin{tabular}{|l|l|l|l|}
\hline Stepping length $(\mathbf{m})$ & $\mathbf{0 . 6 0}$ & $\mathbf{0 . 7 0}$ & $\mathbf{0 . 8 0}$ \\
\hline Mean value of friction coefficient $\mu_{0}$ & 0.152 & 0.161 & 0.162 \\
\hline Standard deviation of friction coefficient $\sigma$ & 0.0113 & 0.00945 & 0.00651 \\
\hline Convergence value of slipping rate $\Phi_{0}$ & 0.0622 & 0.0748 & 0.145 \\
\hline$\mu_{0}+3 \sigma$ & 0.186 & 0.189 & 0.181 \\
\hline
\end{tabular}

Table 2. Calculated parameters in $\Phi-\mu$ curves.

tetramethylthiuram monosulfide (Nocceler TS, Ouchi Shinko Chemical Industrial Co., Ltd., Tokyo, Japan), titanium oxide (A150, Sakai Chemical Industry Co., Ltd., Osaka, Japan), activated carbon AC (Shirosagi C SS, Osaka Gas Chemicals Co., Ltd., Osaka, Japan) and Sodium chloride SC (Nakuru UM-10, Naikai Salt Industries Co., Ltd.,, Okayama, Japan) were added to the composites (MB1-5) obtained in the first mixing process. Here, according to the AC maker, this AC was made from wood, the peak of distribution of holes on AC surface was about $2 \mathrm{~nm}$, the median size of AC was about $50 \mu \mathrm{m}$, the specific surface area was about $900 \mathrm{~m}^{2} / \mathrm{g}$, and the AC 


\begin{tabular}{|l|l|l|l|l|l|l|}
\hline \multicolumn{2}{|c|}{} & MB1 & MB2 & MB3 & MB4 & MB5 \\
\hline Polymer & Isoprene rubber & 100 & 100 & 100 & 100 & 100 \\
\hline Reinforcing filler & Silica & 44 & 51 & 60 & 69 & 80 \\
\hline Plasticizing agent & Oil & 20 & 20 & 20 & 20 & 20 \\
\hline Silane coupling agent & Bis(triethoxysilylpropyl) tetrasulfide & 4.4 & 5.1 & 6.0 & 6.9 & 8.0 \\
\hline \multirow{2}{*}{ Processing aid } & Stearic acid & 2.0 & 2.0 & 2.0 & 2.0 & 2.0 \\
\cline { 2 - 7 } & Zinc oxide & 5.0 & 5.0 & 5.0 & 5.0 & 5.0 \\
\hline Others (antioxidant and vulcanization accelerator) & 3.5 & 3.5 & 3.5 & 3.5 & 3.5 \\
\hline
\end{tabular}

Table 3. Rubber compositions in the first mixing process (unit: phr).

surface was not chemically treated. As to the SC, the purity of SC was $99.59 \%$, and the median size of SC was $11.1 \mu \mathrm{m}$. Rubbers without AC or SC (labelled as R1-5) were prepared using MB1-5, respectively. While the rubbers filled with AC (labelled as AC3, AC4, AC6 and AC7) and the rubbers filled with SC (labelled as SC3, SC4, SC6 and SC7) were made from MB1, MB2, MB4 and MB4, respectively, AC1, AC2, AC5, AC8, SC1, SC2, SC5, SC8 and SC9 were prepared based on MB3 with different content of AC or SC as shown in Table 1. Titanium oxide was added to each rubber to ensure the high intensity of reflected light in friction test using hemisphere specimens. Even the change in physical properties (except density) by adding titanium oxide was negligible, titanium oxide was not added for outsole preparation to compare friction behaviour of outsoles without titanium oxide, because titanium oxide is not always added to outsole of shoes for sale. To control pore size for rubber filled with SC, we used sodium chloride grade with controlled size $(\approx 10 \mu \mathrm{m})$. Table 1 also shows the physical properties of each rubber. Tensile strength and tear strength were measured based on ISO 37:2017 and ISO341:2004, respectively, using dumbbell-like specimens and angle test piece with a nick of specified depth, respectively, by setting head speed at $500 \mathrm{~mm} / \mathrm{min}$. E was defined as the average elastic modulus when strain was $<5.0 \%$ in the tensile strength measurement. For hemisphere specimens, radius of curvature and arithmetical mean height $S_{\text {a }}$ were measured using a One-Shot 3D measuring macroscope (VR3000, Keyence Corporation, Osaka, Japan). $S_{\mathrm{a}}$ was quantified based on the $1.000 \mu \mathrm{m}$ square within bottom top of hemisphere specimens where plane correction was applied in the accompanying software (VR-H1A, Keyence Corporation, Japan). It was confirmed that the radius of curvature and $S_{\mathrm{a}}$ were within $5.21-5.29 \mathrm{~mm}$ and $1.21-1.52 \mu \mathrm{m}$, respectively, among all hemisphere specimens. Surface free energy of each rubber was quantified by contact angle with 1.0- $\mu \mathrm{L}$ ion-exchanged water and diiodomethane (Wako 1st grade, FUJIFILM Wako Pure Chemical Corporation, Osaka, Japan) using a contact angle meter (DMs-401, Kyowa Interface Science Co., Ltd., Saitama, Japan) ${ }^{33}$. The dispersion and polar terms of free energy were within $0.0-0.1 \mathrm{~mJ} / \mathrm{m}^{2}$ and $24.1-26.0 \mathrm{~mJ} / \mathrm{m}^{2}$, respectively. According to the geometrical properties and surface free energy, the difference in these parameters were so minute that real contact formation and friction behaviour could not be affected by these parameters. Figure 1a indicates overall images of hemispheres specimens (R3, AC5 and SC5) and their scanning electron microscope (SEM) images observed by a SEM (JSM-6390A, JEOL Ltd., Tokyo, Japan). Here, for hemisphere specimens and outsole rubber materials filled with SC, the sodium chloride particles on rubber surface was removed by washing in water and drying at room temperature before surface observation and friction tests. SEM images in Fig. 1a explain that air pockets were formed by adding AC and SC, and that the air pocket size was about $0.1 \mu \mathrm{m}$ and $5 \mu \mathrm{m}$, respectively. Using outsoles of all rubbers, footwear (TMM800, size: $27.0 \mathrm{~cm}$, ASICS Corporation, Kobe, Japan) were prepared in a shoe maker (Sanin ASICS Industry Corporation, Sakaiminato, Japan) as shown in Fig. 4a-c.

Friction test using hemisphere specimens. A friction test was conducted using all hemisphere specimens (R1-5, AC1-8 and SC1-9) and contact condition was observed during the friction test. Figure $1 \mathrm{~b}$ shows a schematic view of experimental system. Each hemisphere specimen perpendicularly approached to a water-covered glass surface (084.4L100-45DEG-6P-4SH3.5, SIGMAKOKI Co., Ltd., Saitama, Japan) at $1.00 \mathrm{~mm} / \mathrm{s}$ using an electric cylinder (EASM4NXD010AZMC, Oriental Motor Co., Ltd., Japan) and within $0.01 \mathrm{~s}$ after completion of contacting process. The glass was slid horizontally and linearly at $1.00 \mathrm{~mm} / \mathrm{s}$ using another electric cylinder (EACM4D30AZAC, Oriental Motor Co., Ltd., Japan). Normal force was set at $0.196 \mathrm{~N}$ using the dead weight as shown in Fig. 1b, and friction force was measured using a load cell (TL201Ts, Trinity-Lab Inc., Tokyo, Japan) at $1 \mathrm{kHz}$. In the contact-condition observation, distributions of water, air and real contacts were measured based on intensity in a total reflection method and a light interferometry ${ }^{11}$, and distribution of clearance between rubber and glass was quantified based on the intensity in the total reflection method ${ }^{34}$. As shown in Fig. 1b, in the total reflection method, red light from a light-emitting diode (LED, HLV2-22RD-3 W, CCS Inc., Kyoto, Japan) was penetrated into the glass as totally reflected in the glass (reflect angle was set at $65^{\circ}$ ) using a light guide (LE-OPT-24, OPTEC FA Co., Ltd., Kyoto, Japan) and a mirror (RPB3-20-550, SIGMAKOKI Co., Ltd., Saitama, Japan). In the light interferometry, blue light form LED (HLV2-22BL-3W, CCS Inc., Kyoto, Japan) was perpendicularly inserted in the interface between hemisphere specimen and glass plate through a telecentric lens (TV-2F-110, OPTART Co., Ltd., Tokyo, Japan). The reflected light was observed by a charge-coupled device camera (AT-030MCL, JAI Ltd., Yokohama, Japan) at 12 bit and $100 \mathrm{fps}$ in both total reflection method and light interferometry. The pixel size corresponded to $3.6 \mu \mathrm{m} \times 3.6 \mu \mathrm{m}$. In this study, friction and observation test for each condition was conducted five times. The friction force and contact condition were measured at $d=0.00-$ 
$10.00 \mathrm{~mm}$, and mean values and standard deviation of each parameter were obtained from the results measured at $d=5.00-10.00 \mathrm{~mm}$. Atmosphere temperature and relative humidity were set at $21.8^{\circ} \mathrm{C}$ and $68 \%$, respectively.

Friction test using footwear with a slip meter. The friction test was conducted with a slip meter (SATRA TM144, SATRA Technology Centre Ltd., Kettering, UK) based on ISO 13287 using right footwear with all rubbers, as shown in Fig. 4d. As the toe of footwear was not in contact with a water-covered smooth Mikage stone tile (G603 White, Sakae shokai Co., Ltd., Tajimi, Japan), the angle between outsole and floor was set at $7^{\circ}$. The surface roughness of the floor was measured by a roughness meter (SV-3000S4, Mitutoyo Corporation, Kawasaki, Japan) and $S_{\mathrm{a}}=0.070 \mu \mathrm{m}$. Normal force, sliding velocity and sliding distance $d$ were set at $500 \mathrm{~N}, 300 \mathrm{~mm} / \mathrm{s}$ and $200 \mathrm{~mm}$ respectively. Based on ISO 13287, friction test was conducted 10 times for each outsole materials, and mean value and standard deviation of friction coefficient $\mu$ was calculated from the results in 6th-10th trials at $d=100-200 \mathrm{~mm}$. Atmosphere temperature and relative humidity were $22.6{ }^{\circ} \mathrm{C}$ and $37 \%$, respectively.

Slip-resistance test using shoes in a stepping motion. The slip resistance in stepping motion was measured as shown in Fig. 5a using right footwear with outsole of R1, R3, R5, AC3, AC5, AC7, SC3, SC5 and SC7. Because $\mu$ of shoes was especially sensitive to $E$ and addition of AC or SC in comparison with the content of these addition as shown in Fig. 4e,f, the footwear with R1, R3, R5, AC3, AC5, AC7, SC3, SC5 and SC7 were selected to conduct this test. The water-covered smooth Mikage tile was used as the floor, as well as in the friction test using shoes. Eleven healthy young male adults (age: 22-36 years, height: $1.65-1.91 \mathrm{~m}$, body mass: $52-76 \mathrm{~kg}$, dominant foot: right or left) participated in this trial. All methods/experiments were performed in accordance with relevant guidelines and regulations. The participants were informed of the protocol, and informed consent was obtained from each participant before the experiment. The protocol was approved by the Institutional Review Board of Tohoku University. The participants were asked to wear each footwear and stand still. Then, they were asked to take a single forward step on the floor with a step length of $0.6,0.7$ and $0.8 \mathrm{~m}$. Here, subjects were instructed to make heel contact with the floor in the stepping motion. While the stepping motions were conducted continuously 20 times for each outsole-step length condition, the order of the trial condition was randomized. The contact between shoe and floor in the stepping motion was observed by a digital camera (PowerShot SX700 HS, Sony, Tokyo, Japan) at $60 \mathrm{fps}$. In this chapter, whether a slip occurred or not was defined as whether the slipping distance was more than $0.03 \mathrm{~m}$ or not, based on the previous study ${ }^{35}$. To easily judge the slipping distance by moving during the stepping motion, parallel lines orthogonal to the stepping direction were printed par $1.0 \mathrm{~cm}$ on the floor. Mean value and standard division of slip rate for each condition ( 9 types of outersole and 3 grades of step length) were quantified based on the results of 220 steps (=11 subjects $\times 20$ steps). To avoid a serious slip-and-fall accident during this test, balusters (P-2, Mutsumi Medical Co., Ltd., Osaka, Japan) were set on the both side of subjects; however, no subjects touched these balusters before the heel contacts in stepping motion. The temperature and relative humidity were $17.0^{\circ} \mathrm{C}$ and $33 \%$, respectively.

Received: 17 September 2021; Accepted: 8 December 2021

Published online: 07 January 2022

\section{References}

1. Strandberg, L. The effectof conditions underfoot on falling and overexertion accidents. Ergonomics 28, 131-147 (1985).

2. Leclercq, S., Tisserand, M. \& Saulnier, H. Tribological concepts involved in slipping accident analysis. Ergonomics 38, 197-208 (1995).

3. Babaee, S. et al. Bioinspired kirigami metasurfaces as assistive shoe grips. Nat. Biomed. Eng. https://doi.org/10.1038/s41551-0200564-3 (2020).

4. Perkins, P. J. \& Wilson Shoe, M. P. Slip resistance testing of shoes-new developments. Ergonomics 26, 73-82 (1983).

5. Yamaguchi, T. \& Hokkirigawa, K. Development of a high slip-resistant footwear outsole using a hybrid rubber surface pattern. Ind. Health 52, 414-423 (2014).

6. Nishi, T., Moriyasu, K., Harano, K. \& Nishiwaki, T. Influence of dewettability on rubber friction properties with different surface roughness under water/ethanol/glycerol lubricated conditions. in Tribology Online vol. 11 601-607 (Japanese Society of Tribologists, 2016).

7. Ramsay, H. T. \& Senneck, C. R. Anti-slip studs for safety footwear. Appl. Ergon. 3, 219-223 (1972).

8. Martin, P., Silberzan, P. \& Brochard-Wyart, F. Sessile droplets at a solid/elastomer interface. Langmuir 13, 4910-4914 (1997).

9. Martin, P. \& Brochard-Wyart, F. Dewetting at Soft Interfaces. Phys. Rev. Lett. 80, 3296-3299 (1998).

10. Nishi, T., Yamaguchi, T., Shibata, K. \& Hokkirigawa, K. Optimizing the frictional behavior of partially wetting soft contacts as measured with hydrogel covered silicones. Tribol. Int. 153, 106586 (2021).

11. Nishi, T., Yamaguchi, T., Shibata, K. \& Hokkirigawa, K. Friction behavior of silicone rubber hemisphere under non-uniform wetting states: With water droplets in air or air bubbles in water. Tribol. Int. 155, 106769 (2021).

12. de Gennes, P. G., Brochard-Wyart., F. \& Quéré, D. (Eds.) Special interfaces. In Capillarity and Wetting Phenomena: Drops, Bubbles, Pearls, Waves (eds de Gennes, P. G. et al.) 215-259 https://doi.org/10.1007/978-0-387-21656-0_9 (Springer, 2004).

13. Yamaguchi, T. et al. Development of new footwear sole surface pattern for prevention of slip-related falls. Saf. Sci. 50, 986-994 (2012).

14. Ido, T. et al. Sliding friction characteristics of styrene butadiene rubbers with varied surface roughness under water lubrication. Tribol. Int. 133, 230-235 (2019).

15. Chen, D., Hu, M., Huang, C. \& Zhang, R. CHAPTER 4 Preparation and properties of natural rubber composites and nanocomposites. In Natural Rubber Materials : Composites and Nanocomposites Vol. 2 (eds Thomas, S. et al.) 112-135 https://doi.org/10. 1039/9781849737654. (The Royal Society of Chemistry, 2014).

16. Omnès, B., Thuillier, S., Pilvin, P., Grohens, Y. \& Gillet, S. Effective properties of carbon black filled natural rubber: Experiments and modeling. Compos. Part A Appl. Sci. Manuf. 39, 1141-1149 (2008).

17. Farida, E., Bukit, N., Ginting, E. M. \& Bukit, B. F. The effect of carbon black composition in natural rubber compound. Case Stud. Therm. Eng. 16, 100566 (2019). 
18. Hagemann, N. et al. Activated carbon, biochar and charcoal: Linkages and synergies across pyrogenic carbon's ABCs. Water 10, $182(2018)$.

19. Sun, K. \& Jiang, J. C. Preparation and characterization of activated carbon from rubber-seed shell by physical activation with steam. Biomass Bioenergy 34, 539-544 (2010).

20. Özçimen, D. \& Ersoy-Meriçboyu, A. Characterization of biochar and bio-oil samples obtained from carbonization of various biomass materials. Renew. Energy 35, 1319-1324 (2010).

21. Gupta, V. K., Nayak, A., Agarwal, S. \& Tyagi, I. Potential of activated carbon from waste rubber tire for the adsorption of phenolics: Effect of pre-treatment conditions. J. Colloid Interface Sci. 417, 420-430 (2014).

22. Kan, T., Strezov, V. \& Evans, T. J. Lignocellulosic biomass pyrolysis: A review of product properties and effects of pyrolysis parameters. Renew. Sustain. Energy Rev. 57, 1126-1140 (2016).

23. Khalil, H. P. S. A., Noriman, N. Z., Ahmad, M. N., Ratnam, M. M. \& Fuaad, N. A. N. Polyester composites filled carbon black and activated carbon from bamboo (Gigantochloa scortechinii): Physical and mechanical properties. J. Reinf. Plast. Compos. 26, 305-320 (2007).

24. Lay, M., Rusli, A., Abdullah, M. K., Abdul Hamid, Z. A. \& Shuib, R. K. Converting dead leaf biomass into activated carbon as a potential replacement for carbon black filler in rubber composites. Compos. Part B Eng. 201, 108366 (2020).

25. Ao, G., Hu, Q. \& Kim, M. Properties of activated carbon blacks filled SBR rubber composites. Carbon Lett. 9, 115-120 (2008).

26. Sahli, R. et al. Evolution of real contact area under shear and the value of static friction of soft materials. Proc. Natl. Acad. Sci. U. S. A. 115, 471-476 (2018).

27. Sahli, R. et al. Shear-induced anisotropy in rough elastomer contact. Phys. Rev. Lett. 122, 214301 (2019).

28. Hertz, H. Ueber die Berührung fester elastischer Körper. J. für die reine und Angew. Math. (Crelles J.) 1882, 156-171 (1882).

29. Bowden, F. P. \& Tabor, D. The friction and lubrication of solids part II. Phys. Today 17, 72 (1964).

30. Moore, D. F. \& Geyer, W. A review of adhesion theories for elastomers. Wear 22, 113-141 (1972).

31. Momozono, S., Iguchi, Y., Oshikiri, K., Nakamura, K. \& Kyogoku, K. Effects of interfacial free energy on adhesive friction behavior of elastomer surfaces under wet conditions. in 5th World Tribology Congress vol. 4 3208-3211 (2013).

32. Nishi, T. Effects of wettability on tribology of soft matter. Toraibarojisuto/J. Jpn. Soc. Tribol. 64, 588-593 (2019).

33. Kaelble, D. H. Dispersion-polar surface tension properties of organic solids. J. Adhes. 2, 66-81 (1970).

34. Nishi, T., Moriyasu, K. \& Nishiwaki, T. Precise measurement of clearance between two substrates using evanescent waves. Tribol. Online 12, 251-256 (2017).

35. Yamaguchi, T., Hsu, J., Li, Y. \& Maki, B. E. Efficacy of a rubber outsole with a hybrid surface pattern for preventing slips on icy surfaces. Appl. Ergon. 51, 9-17 (2015).

\section{Author contributions}

T.N.: Conceived and designed the experiments, Performed the experiments, Analyzed the data, Contributed materials/analysis tools, and Wrote the paper. T.Y.: Conceived and designed the experiments, Analyzed the data, Contributed materials/analysis tools, and Wrote the paper. K.H.: Conceived and designed the experiments.

\section{Competing interests}

The authors declare no competing interests.

\section{Additional information}

Correspondence and requests for materials should be addressed to T.N.

Reprints and permissions information is available at www.nature.com/reprints.

Publisher's note Springer Nature remains neutral with regard to jurisdictional claims in published maps and institutional affiliations.

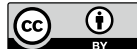

Open Access This article is licensed under a Creative Commons Attribution 4.0 International License, which permits use, sharing, adaptation, distribution and reproduction in any medium or format, as long as you give appropriate credit to the original author(s) and the source, provide a link to the Creative Commons licence, and indicate if changes were made. The images or other third party material in this article are included in the article's Creative Commons licence, unless indicated otherwise in a credit line to the material. If material is not included in the article's Creative Commons licence and your intended use is not permitted by statutory regulation or exceeds the permitted use, you will need to obtain permission directly from the copyright holder. To view a copy of this licence, visit http://creativecommons.org/licenses/by/4.0/.

(C) The Author(s) 2022 